\title{
Medical Assistance in Dying: What Does It Mean for Neurologists and Neurosurgeons?
}

Keywords: Medical assistance in dying, neurosurgery, neurology

In February of 2015, the Supreme Court of Canada (SCC) struck down the Criminal Code of Canada's prohibition against physician-assisted suicide on the grounds that it violated the Charter of Rights and Freedoms' right to "life, liberty, and security of the person." The SCC further charged parliament to enact a legislative framework for physician-assisted dying within a year (later extended to 18 months). With the passage of Bill C-14 into law on 17 June 2016, physicians are no longer considered to have committed homicide when participating in physicianassisted death, or "medical assistance in dying" (MAID) as C-14 calls it. $^{2}$

In this issue of the $C J N S$, Barry et al. ${ }^{3}$ present a position statement on MAID from the Canadian Neurosurgical Society (CNSS). The authors are to be commended for taking a proactive stance on MAID, one that resulted from consultation with CNSS membership through a survey as well as the deliberations of a special CNSS subcommittee struck after the SCC's Carter decision. The position statement takes strong stances in support of a physician's right to conscientious objection and the importance of access to palliative care at the end of life.

C-14 defines medical assistance in dying as the administering or prescribing of a substance to a person, at their request, that causes their death. C-14 restricts MAID to those 18 or older who voluntarily request and consent to it, and who have a "grievous and irremediable medical condition," defined as a serious and incurable illness, a disease or disability causing intolerable physical or psychological suffering in one whose death is "reasonably foreseeable." Mature minors, patients with psychiatric disorders, and advanced directives requesting MAID once a patient loses the capacity to consent are all excluded under the legislation.

Neurosurgeons and neurologists, by the very nature of our specialties, treat patients with medical conditions that are likely to meet the eligibility criteria for MAID, including malignant brain tumours, multiple sclerosis, and amyotrophic lateral sclerosis, but we also treat many conditions that under the current legislation are not eligible for MAID, such as intractable chronic pain, severe traumatic brain and spinal cord injuries, and advanced dementing illnesses where patients are no longer competent to make medical decisions. Ironically, it is not clear that Kay Carter, the petitioner in the Carter vs. Canada case, who suffered from severe spinal stenosis, would have been eligible for MAID under C-14. Indeed, the constitutionality of the legislation has already been challenged. ${ }^{4}$

Although not explicit in the legislation, the government has been clear that they see C-14 as the beginning of the process of creating a national framework for MAID, with the possibility of further legislation expanding its scope to mature minors, psychiatric illness, and the use of advanced directives in the future.

According to Health Canada, a total of 803 medically assisted deaths have occurred in Canada since the passage of C-14 up to the end of $2016 .{ }^{5}$ Despite this, it is clear that the debate surrounding MAID in Canada is not over. Issues that may be of considerable interest to neurosurgeons and neurologists include whether advanced directives for MAID should be allowed, and whether patients with non-terminal conditions should be eligible. Many of the conditions we treat impact on an individual's capacity to make autonomous decisions, either in a gradual manner, such as Alzheimer's disease, or suddenly, such as with stroke or traumatic brain injury. Patients such as these are not eligible for MAID under C-14, nor are those with intractable chronic pain or severe disability, such as complete spinal cord injury. Even the definition of "reasonably foreseeable" is vague (perhaps deliberately so), and this is not a term commonly used in medicine. Taken to an absurd extreme, one's death is foreseeable with certainty from the moment of birth.

Finally, issues surrounding access to MAID, as well as ensuring appropriate expertise and training and regulatory oversight of those healthcare providers who choose to participate in it, remain unresolved. It remains to be seen what role neurosurgeons and neurologists will play in the day-to-day provision of medical assistance in dying in Canada, but it is critical that a reasoned, informed debate of involved stakeholders continue, recognizing, as the authors state, that "compassionate physicians with deep moral convictions exist on both sides of the debate."

\section{Disclosures}

Dr. McDonald is the Vice President of the Canadian Neurosurgical Society.

Patrick J. McDonald

Division of Neurosurgery, BC Children's Hospital

University of British Columbia, 4480 Oak Street, Room K3-216

Vancouver, British Columbia V6H 3V4, Canada

Email: Patrick.McDonald@cw.bc.ca

\author{
REFERENCES \\ 1. Carter v. Canada (Attorney General), SCC 5, [2015], 1 S.C.R. 331; \\ 2015.
}

Received May 4, 2017. ACCEPTED MAy 9, 2017. 
2. Bill C-14, An Act to Amend the Criminal Code and to Make Related Amendments to Other Acts (Medical Assistance in Dying). 1st Session, 42nd Parliament. Available at: http://laws-lois. justice.gc.ca/PDF/2016 3.pdf.

3. Barry S, Ekong E, Wheelock BW, et al. MAID and the neurosurgeon: position statement of the CNSS. Can J Neurol Sci. 2017. In press.

4. Stone L, Fine S. BC woman, rights group file legal challenge against assisted-dying law. The Globe and Mail, June 27, 2016.
Available at: https://www.theglobeandmail.com/news/politics/ rights-group-launches-legal-challenge-of-assisted-dying-law/article 30623211/.

5. Interim Update on Medical Assistance in Dying in Canada: June 17 to December 31, 2016. Ottawa: Health Canada. Available at: https://www.canada.ca/en/health-canada/services/publications/ health-system-services/medical-assistance-dying-interim-report-dec2016.html. 